\title{
SECONDARY HYPERTENSION IN ACUTE POISONING IN CHILDREN AND ADOLESCENTS
}

\author{
Cristina Iolanda Vivisenco, Coriolan Emil Ulmeanu \\ „, Grigore Alexandrescu” Emergency Children's Hospital, Bucharest \\ Pediatrics Department, „, Carol Davila” University of Medicine and Pharmacy, \\ Bucharest
}

\begin{abstract}
Introduction. Exposure to various cardiovascular and non-cardiovascular drugs, drugs of abuse, chemicals and plants may cause secondary hypertension. The authors report their personal experience related to secondary hypertension due to acute poisoning in children and adolescents.

Materials and methods. We conducted a 24 month prospective study that included 151 children and adolescents with acute poisoning who developed cardiovascular abnormalities. In order to detect cases of secondary hypertension, vital signs were assessed on admission and in evolution, considering the normal values by age. Results. $11.1 \%$ of all cases with acute poisoning admitted and treated in our department have associated cardiovascular impairment. Of these, $18.5 \%$ were cases of secondary hypertension. The main cause of hypertension in the study group was exposure to organophosphate insecticides, followed by exposure to sympathomimetic drugs. We noticed a dual effect exerted by organophosphate insecticides. At the beginning patients experienced a short period of tachycardia and hypertension, followed by the installation of the classic cholinergic feature of acute poisoning with organophosphate insecticides, with bradycardia and / or hypotension. All cases of hypertension were transient, self-limiting elevations of blood pressure, which did not require association of antihypertensive agents in the therapeutical approach.

Conclusion. In children and adolescents, acute poisoning may be complicated by hypertension, which is mostly mild and transient. Vital signs monitoring is essential to address these cases. Medical staff must know thoroughly age peculiarities, including reference ranges for blood pressure in children and adolescents.
\end{abstract}

Keywords: secondary arterial hypertension, acute poisoning, organophosphate insecticides, child, adolescent

\section{INTRODUCTION}

Blood pressure is a vital parameter that correlates directly with heart rate, stroke volume and systemic vascular resistance. Maintaining blood pressure in normal ranges is dependent on the proper functioning of the heart and vessels. Systolic component reflects the inotropic function of the myocardium, while diastolic component reflects the vascular tone $(1,2)$.

Elevated blood pressure due to underlying causes, which can often be identified and corrected, defines secondary hypertension. Exposure to various cardiovascular and non-cardiovascular drugs, drugs of abuse, chemicals and plants may cause secondary hypertension $(3,4)$. In this study, we report our experience related to cardiovascular toxicity and secondary hypertension in acute poisoning in children and adolescents.

\section{MATERIALS AND METHODS}

From October 2011 to September 2013 we conducted in the Toxicology - Intensive Care Department at „Grigore Alexandrescu” Emergency Children's Hospital in Bucharest a prospective, observational and descriptive study that included a group of 151 patients aged between 0 and 18, admitted with a diagnosis of acute poisoning, who developed from the presentation or in evolution 
cardiovascular abnormalities. Demonstration of cardiovascular toxicity involved identifying at least one of the following: rhythm and conduction disturbances, abnormal blood pressure, acute coronary syndromes, congestive heart failure, cardiogenic and/or vasoplegic shock. Patients with known cardiac disease previous to toxic exposure and those who, although admitted for acute poisoning with potentially cardiotropic and/or vasculotropic agents, did not develop any impairment of the cardiovascular system, were excluded from the study. For this study we requested and obtained the approval of the hospital's ethics committee.

In order to detect the cases of secondary hypertension, vital signs were assessed on admission and in evolution, considering the normal values by age. Blood pressure was measured with appropriate size cuffs by oscillometric method using Dinamap monitors. To analyze the values obtained in the age group 0-5 years we used charts published by Park et al in 1989 and for children older than 5 years we used charts published by the same group in 2005 $(5,6)$. We considered to be abnormal the values that were less than 5th percentile and greater than 95th percentile.

\section{RESULTS}

In the 24 month period of study 1,358 cases of acute poisoning were admitted and treated in our department. Of these, we included in our study 151 cases which presented at admission or during hospitalization cardiovascular impairment, their prevalence was $11.1 \%$. Table 1 presents the etiology of acute poisoning in the study group.

In Table 2 we synthesized data obtained by blood pressure monitoring in the study group. Hypertension was recorded in 28 cases, representing $18.5 \%$ of all cases with toxic cardiovascular impairment. In 5 cases, patients have experienced transient hypertension at the onset of acute poisoning, followed by hypotension. All cases of hypertension identified in the personal study were transient, self-limiting elevations of blood pressure. Continuous monitoring of vital signs showed spontaneous recovery of blood pressure to normal ranges, without the need for antihypertensive agent association in the therapeutical approach of this patients.

TABLE 1. The etiology of poisoning in the study group

\begin{tabular}{|c|c|c|}
\hline Etiology & Number of cases & Percent \\
\hline \multicolumn{3}{|l|}{ Drugs } \\
\hline Digitalis glycosides: digoxin & 1 & 0.66 \\
\hline$\beta$-receptor antagonists: metoprolol, bisoprolol, carvedilol, Distonocalm ${ }^{\circ}$ & 10 & 6.62 \\
\hline Central $\alpha_{2}$-receptor agonist: clonidine, moxonidine & 4 & 2.65 \\
\hline Calcium channel-blocking agents: ditiazem, nifedipine & 2 & 1.32 \\
\hline Sodium channel-blocking antidysrhythmics: propafenone & 1 & 0.66 \\
\hline Nitrates: pentaerythritol tetranitrate & 1 & 0.66 \\
\hline Tryciclic antidepressants: amitriptyline, clomipramine, imipramine & 4 & 2.65 \\
\hline Serotonergic antidepressants: tianeptin, venlafaxine, escitalopram & 3 & 1.99 \\
\hline Neuroleptics: haloperidol, risperidone, olanzapine, quetiapine, aripiprazole & 8 & 5.3 \\
\hline Anticonvulsants:carbamazepine, valproate, oxcarbazepine & 22 & 14.57 \\
\hline Dopamine agonists: bromocriptine & 1 & 0.66 \\
\hline Sympathomimetics: epinephrine, salbutamol, phenylephrine & 21 & 13.91 \\
\hline Nasal decongestants: naphazoline \pm ephedrine, trimazoline + phenylephrine & 4 & 2.65 \\
\hline Methylxanthines: theophylline & 3 & 1.99 \\
\hline Centrally acting muscle relaxants: baclofen & 1 & 0.66 \\
\hline Antimalarial drugs: mefloquine+artesunate & 1 & 0.66 \\
\hline Local anesthetics: lidocaine & 1 & 0.66 \\
\hline Thyroid hormones: levothyroxine & 2 & 1.32 \\
\hline Poly-drug poisoning & 22 & 14.57 \\
\hline Drugs of abuse & 8 & 5.3 \\
\hline Anabolic substances & 1 & 0.66 \\
\hline \multicolumn{3}{|l|}{ Rural toxicants } \\
\hline Cholinesterase-inhibiting insecticides (organophosphates) & 12 & 7.95 \\
\hline Nitrites (well-water) & 7 & 4.64 \\
\hline \multicolumn{3}{|l|}{ Household toxicants } \\
\hline Carbon monoxide & 11 & 7.28 \\
\hline Total & 151 & 100 \\
\hline
\end{tabular}


TABLE 2. Blood pressure - values in study group

\begin{tabular}{|l|c|}
\hline Blood pressure & $\mathbf{n}(\%)$ \\
\hline Low & $24(15.89)$ \\
Normal & $99(65.56)$ \\
High & $23(15.23)$ \\
Low + high & $5(3.31)$ \\
\hline Total & $151(100)$ \\
\hline
\end{tabular}

The etiology of hypertension in the analyzed group is summarized in Table 3. The main cause of hypertension was exposure to organophosphate insecticides, followed by exposure to sympathomimetic drugs.

TABLE 3. Hypertension etiology in study group

\begin{tabular}{|l|c|}
\hline & $\begin{array}{c}\text { Number of } \\
\text { cases }\end{array}$ \\
\hline Central $\alpha_{2}$-receptor agonist: clonidine & 1 \\
\hline Serotonergic antidepressants: venlafaxine & 1 \\
\hline Neuroleptics: risperidone, aripiprazole & 2 \\
\hline Anticonvulsants: carbamazepine & 3 \\
\hline $\begin{array}{l}\text { Sympathomimetics: salbutamol, epinephrine, } \\
\text { phenylephrine }\end{array}$ & 5 \\
\hline Imidazoline decongestants & 2 \\
\hline Centrally acting muscle relaxant: baclofen & 1 \\
\hline Local anesthetics: lidocaine & 1 \\
\hline Poly-drug ingestion & 3 \\
\hline Amphetamines & 1 \\
\hline Anabolics & 1 \\
\hline Organophosphate insecticides & 7 \\
\hline Total & 28 \\
\hline
\end{tabular}

Diazinon was the organophosphate insecticide found in all 7 cases. Those five patients that showed in evolution periods of both hypertension and hypotension were cases of acute poisoning with diazinon. They presented at the onset of acute poisoning a short period of tachycardia and hypertension, followed by the classic cholinergic feature of acute poisoning with organophosphate insecticides, with bradycardia and/or hypotension.

Two thirds $(n=19)$ of cases of secondary hypertension were caused by pharmaceutical agents, alone or in combination. In one case of acute poisoning with clonidine the patient had a transient episode of hypertension at the onset of acute poisoning. The other cases of drug poisoning which associated hypertension were caused by non-cardiovascular pharmaceutical agents. Of these, as mentioned above, the first place was occupied by sympathomimetic drugs. Sympathomimetic exposure was unintentional in all cases, by ingestion of intranasal, oral or inhalation solutions by small children or by administration in the nebulizer of wrong doses of epinephrine and, respectively sal- butamol by caregivers. A similar way of toxic exposure we observed for imidazole-based nasal decongestants, alone or in combination with sympathomimetics. Thus, we found hypertension in 2 cases of ingestion and, respectively accidental intranasal administration of toxic doses of naphazoline \pm ephedrine.

We found hypertension in a significant number of cases, which were exposures to drugs with pharmacological action on the central nervous system: anticonvulsants, tricyclic and serotonergic antidepressants, neuroleptics. 3 of these were cases of drug coingestion: carbamazepine + paroxetine + diazepam, valproate + amitriptyline and tianeptine + amitriptyline.

\section{DISCUSSION}

Vital signs monitoring is an essential step in the diagnostic approach of patients with acute poisoning. Blood pressure can be modified by numerous toxic substances which, once absorbed into the body, interact with the chemical processes that normally take place in the nerve endings of postganglionic sympathetic fibers in the vascular and cardiac smooth muscle $(1,7)$. The two basic mechanisms by which high blood pressure occurs in poisoned patients are increased vascular resistance and/or increased inotropism. Vasoconstriction is most commonly involved in the occurrence of toxicant-induced hypertension and is produced by stimulation of $\alpha 1$-adrenergic receptors. $\beta 1$-adrenergic receptor stimulation increases myocardial contractility $(1,3,7)$. Most toxicants (ex. amphetamines, epinephrine, phenylephrine, ephedrine) generate a diffuse activation of adrenergic receptors by increasing catecholamine release or by inhibiting their reuptake and degradation. However, $\alpha 1$ and $\beta 1$ effects dominate, which will generate hypertension, that is specific for the sympathomimetic toxidrome $(1,3,8)$.

Both systolic and diastolic component of blood pressure should be assessed in the poisoned patient. $\alpha 1$-adrenergic receptor agonists will increase both components of blood pressure, while nonselective $\beta$-adrenergic agonists may cause an increase of differential blood pressure. This is explained by the increase in systolic blood pressure as a result of $\beta 1$-adrenergic receptor stimulation and decreased diastolic blood pressure as a result of vasodilation mediated by $\beta 2$-adrenergic receptors. Since $\beta 1$-adrenergic receptors increase contractility and heart rate, and $\beta 2$-adrenergic receptors generate vasodilation, only those substances that act predomi- 
nantly on $\beta 1$ subtype might generate hypertension. In overdose, however, the specificity is no longer maintained and $\beta 2$-adrenergic agonists may increase inotropism and chronotropism (9-11). We found this feature in our study, in 3 cases of exposure to toxic doses of salbutamol.

We also identified one case of transient hypertension secondary to clonidine acute poisoning. In therapeutic doses, it stimulates central $\alpha 2$-adrenergic receptors, exerting antihypertensive and sedative effects $(1,12)$. Toxic doses of clonidine, however, stimulate peripheral adrenergic $\alpha 2$ receptors too, generating norepinephrine release, vasoconstriction and hypertension. This paradoxical effect on blood pressure is short-lived, being inhibited by more potent central effects. $(13,14)$. Based on clonidine molecule a number of imidazole derivatives (naphazoline, oxymetazoline, xylometazoline), used as nasal or eye decongestants, were synthesized. These preparations are common in pediatric acute poisoning, causing, due to similar toxicity with central $\alpha 2$-adrenergic agonists, marked depression of the central nervous system, respiratory failure and cardiovascular impairment $(15,16)$. We found 2 such cases in our study, both being naphazoline acute accidental poisoning.

Is very interesting the finding of a dual mechanism of action that is possessed by cholinesteraseinhibiting insecticides. These toxicants have both sympathetic and parasympathetic activity, which explains the changes seen in study patients. Cardiovascular effects are unpredictable and are often changing in poisoning evolution. At the onset, acetylcholine stimulates nicotinic receptors from gan- glionic sympathetic neurons, leading to tachycardia and mild hypertension. Subsequently the classic cholinergic toxidrome with bradycardia and hypotension installs, through muscarinic receptors stimulation or ganglionic transmission blockade by hyperpolarization (17-19).

In general, secondary hypertension due to acute poisoning is mild and transient, in the literature being rarely described cases of severe hypertension caused by toxicants, complicated with encephalopathy, stroke or irreversible renal failure $(20,21)$. In the absence of specific guidance for the treatment of toxicant-induced hypertension, initial antihypertensive treatment aims to neutralize the underlying toxic mechanism (22). In the study group the increase in blood pressure was transient in all cases and did not require therapeutic intervention with hypotensive pharmaceutical agents.

\section{CONCLUSION}

Child and adolescent acute poisoning can be complicated by hypertension, mostly mild and transient. Etiologic agents involved are very varied, from drugs belonging to cardiovascular and, in particular, noncardiovascular pharmacological classes, to drugs of abuse or insecticides. Even some antihypertensive drugs can cause in toxic doses paradoxical hypertension. Vital signs monitoring, both at presentation and in evolution, is essential to address these cases. Medical staff who manage this pathology in children and adolescents must know thoroughly age peculiarities, including reference ranges for blood pressure.

\section{$\overline{\text { REFERENCES }}$}

1. Hessler R.A. Cardiovascular Principles. In Flomenbaum NE, Goldfrank LR, Hoffman R.S., Howland M.A., Lewin N..A, Nelson L.S., editors. Goldfrank's Toxicologic Emergencies. 8th ed. New York, USA: McGraw-Hill; 2006. p. 364-379.

2. Kang Y.J. Toxic Responses of the Heart and Vascular System. In Klaassen C. Casarett and Doull's Toxicology The Basic Science of Poisons. 7th ed. New York, USA: McGraw-Hill; 2008. p. 699-740.

3. Onusko E. Diagnosing Secondary Hypertension. Am Fam Physician. 2003; 67(1): p. 67-74.

4. Gaudreault P., Cremer R., Lacroix J., Lheureux P. Intoxications: generalites. In Lacroix J, Gauthier M, Hubert P, Leclerc F, Gaudreault P, editors. Urgences et soins intensifs pediatriques. 2nd ed. Quebec, Canada: CHU Sainte-Justine; 2007. p. 1033-1050.

5. Gyamlani G., Geraci S.A. Secondary hypertension due to drugs and toxins. South Med J. 2007; 1007: p. 692-9.

6. The fourth report on the diagnosis, evaluation, and treatment of high blood pressure in children and adolescents. National High Blood

Pressure Education Program Working Group on High Blood Pressure in Children and Adolescents. Pediatrics. 2004; 114 (2 Suppl 4th Report): p. 555-76.

7. Park M.K., Menard S.M. Normative oscillometric blood pressure values in the first 5 years in an office setting. Am J Dis Child. 1989; 143(7): p. 860-4.

8. Park M.K., Menard S.W., Schoolfield J. Oscillometric blood pressure standards for children. Am J Dis Child. 1989; 143(7): p. 860-4.

9. Yu J.H., Weng Y.M., Chen K.F. Triage vital signs predict in-hospital mortality among emergency department patients with acute poisoning: a case control study. BMC Health Services Research. 2012; 12:262.

10. Brent J. Cardiovascular Instability Caused by Drugs or Chemicals. In Ford M, Delaney KA, Ling L, Erickson T. Clinical Toxicology. 1st ed. Philadelphia, Pennsylvania, USA: Saunders; 2001. p. 177-83.

11. Patel M.M., Benowitz N. Cardiac Conduction and Rate Disturbances. In Brent J, Wallace K, Burkhart K. Critical Care Toxicology Diagnosis 
and Management of the Critically Poisoned Patient. 1st ed. Philadelphia, USA: Elsevier Mosby; 2005. p. 241-260.

12. Newton G.E., Azevedo E.R., Parker J.D. Inotropic and sympathetic responses to the intracoronary infusion of a beta2-receptor agonist: a human in vivo study. Circulation. 1999; 99(18): p. 2402-7.

13. Brodde O.E., Michel M.C. Adrenergic and muscarinic receptors in the human heart. Pharmacol Rev. 1999; 51(4): p. 651-90.

14. Cekici L., Valipour A., Kohansal R., Burghuber O.C. Short-term effects of inhaled salbutamol on autonomic cardiovascular control in healthy subjects: a placebo-controlled study. Br J Clin Pharmacol. 2009; 67(4): p. 394-402.

15. Farooqi M., Seifert S., Kunkel S., Johnson M., Benson B. Toxicity from a clonidine suspension. J Med Toxicol. 2009; 5(3): p. 130-3.

16. Talke P.O., Caldwell J.E., Richardson C.A. The effects of clonidine on human digital vasculature. Anesth Analg. 2000; 91(4): p. 793-7.

17. Lilja M., Hakala M., Jounela A.J. Hypertension after clonidine overdose. A case report. Ann Clin Res. 1984; 16(1): p. 10-2.
18. Bucaretchi F., Dragosavac S., Vieira R.J. Acute exposure to imidazoline derivatives in children. J Pediatr (Rio J). 2003; 79(6): p. 519-24.

19. Musshoff F., Gerschlauer A., Madea B. Naphazoline intoxication in a child-a clinical and forensic toxicological case. Forensic Sci Int. 2003; 134(2-3): p. 234-7.

20. Saadeh A.M., Farsakh N.A., al-Ali M.K. Cardiac manifestations of acute carbamate and organophosphate poisoning. Heart. 1997; 77(5): p. 461-4.

21. Ludomirsky A., Klein H.O., Sarelli P. Q-T prolongation and polymorphous ("torsade de pointes") ventricular arrhythmias associated with organophosphorus insecticide poisoning. Am J Cardiol. 1982; 49(7): p. 1654-8.

22. Murphy N.G., Benowitz N.L., Goldschlager N. Cardiovascular Toxicology. In Shannon M.W., Borron S.W., Burns M.J., editors. Haddad and Winchester's Clinical Management of Poisoning and Drug Overdose. 4th ed. Philadelphia, USA: Saunders Elsevier; 2007. p. 133-165. 